\title{
Manoel Balthazar Pereira Diegues Júnior: contributos à modernização da educação alagoana
}

\author{
Manoel Balthazar Pereira Diegues Júnior: contributions to the \\ modernization of Alagoas education
}

\author{
Edna Telma Fonseca e Silva Vilar \\ Doutorado em Educação \\ Universidade Federal da Bahia - UFBA \\ Salvador, Bahia - Brasil \\ edna.telma@ufba.br
}

\begin{abstract}
Resumo: Este artigo discute em que medida Manoel Balthazar Pereira Diegues Júnior contribuiu para a modernização da educação alagoana. A pesquisa histórico-documental e de abordagem (auto)biográfica foi realizada a partir do entrecruzamento de fontes, tais como imprensa e impressos produzidos pelo ou sobre o citado educador, que ocupou cargos e funções públicas, desde o último quartel do século XIX aos primeiros decênios do século XX. A atuação de Diegues Júnior é discutida, recorrendo-se as atribuições de intelectual e expert, não para fins de enquadramento, mas sobretudo, para reafirmar que ao atuar em prol da educação alagoana teve sua expertise demandada e reconhecida pelo Estado e por seus coetâneos, tendoa mobilizado em diversas situações por meio de posicionamentos, práticas e produções, a exemplo da elaboração de obras solicitadas ou mesmo por sua iniciativa como professor.
\end{abstract}

Palavras-chave: história da educação; biografia; intellectual; expert; modernização da educação alagoana.

Abstract: This article discusses the extent to which Manoel Balthazar Pereira Diegues Júnior contributed to the modernization of education in Alagoas. The historical-documentary research and (auto)biographical approach was carried out from the intersection of sources, such as press and printed matter produced by or about the aforementioned educator, who held public positions and functions, from the last quarter of the 19th century to the first decades of the 20th century. Diegues Júnior work is discussed, using the powers of intellectual and expert, not for purposes of framing, but above all, to reaffirm that when acting for the education of Alagoas his expertise was demanded and recognized by the State and its contemporaries, having mobilized her in various situations through positions, practices and productions, such as the elaboration of works requested works or even by her initiative as a teacher.

Key-words: history of education; biography; intellectual; expert; modernization of alagoas education.

Cite como

(ABNT NBR 6023:2018)

SILVA VILAR, Edna Telma Fonseca e. Manoel Balthazar Pereira Diegues Júnior: contributos à modernização da educação alagoana. Dialogia, São Paulo, n. 37, p. 1-16, e19753, jan./abr. 2021. Disponível em: https://doi.org/10.5585/dialogia.n37.19753.

American Psychological Association (APA)

Silva Vilar, E. T. F. (2021, jan./abr.). Manoel Balthazar Pereira Diegues Júnior: contributos à modernização da educação alagoana. Dialogia, São Paulo, 37, p. 1-16, e19753. https://doi.org/10.5585/dialogia.n37.19753 


\section{Introdução}

Este artigo constituiu-se na interseção entre as perspectivas teórico-metodológicas da História de Intelectuais e (Auto)Biografias no âmbito das pesquisas em História da educação, visando discutir os contributos do educador Manoel Balthazar Pereira Diegues Júnior (1852-1922) à modernização da educação alagoana.

Para tanto, recorreu-se a trajetória de atuação do citador educador, que ocupou cargos e funções públicas, desde o último quartel do século XIX aos primeiros decênios do século XX. A atuação de Diegues Júnior é discutida, recorrendo-se as atribuições de intelectual e/ou expert' não para fins de enquadramento, mas sobretudo, para reafirmar que ao atuar em prol da educação alagoana teve sua expertise demandada e reconhecida pelo Estado e por seus contemporâneos, tendo-a mobilizado em diversas situações por meio de posicionamentos, práticas e produções, a exemplo da elaboração de obras solicitadas pelo Estado ou por sua iniciativa como professor.

$\mathrm{Na}$ investigação, recorreu-se ao entrecruzamento de fontes documentais localizadas em suportes como imprensa e impressos, incluindo-se os paratextos com os quais Diegues Júnior apresentou obras de sua autoria; bem como o Relatório ${ }^{2}$ que produziu na condição de Diretor da Instrução Pública, além de ordenamentos ${ }^{3}$ publicados em jornais; biografias e homenagens a ele destinada.

O artigo está organizado de modo a apresentar o educador em tela em notas (auto)biográficas, dialogando-se com o referencial relativo a essa abordagem em perspectiva histórico-documental para em seguida analisar aspectos de sua atuação em prol da modernização da educação alagoana; recorrendo também a discussão relativa as nominações já citadas, em articulação com as fontes.

Por fim, apresentam-se as considerações finais, destacando-se da atuação de Diegues Júnior, os contributos à demanda para organizar e/ou modernizar a educação alagoana, ora feita pelo Estado, ora por iniciativa própria, reafirmando-se então a sua representação como homem de letras e de "[...] inteligência multiforme servida por uma copiosa erudição." (COSTA, 1927, p. 42).

\footnotetext{
${ }^{1}$ Tais categorias vêm sendo discutidas no âmbito das pesquisas do Grupo de Estudos e Pesquisas sobre História da Educação Matemática (GHEMAT).

${ }^{2}$ No mencionado Relatório, Diegues Júnior (1892, p. 8) salientou ser indispensável “[...] dar aos mestres remuneração que os ponha a salvo das mais urgentes necessidades e garantias que lhes deem prestígio perante a sociedade". Ademais, a formação dos professores (hoje nominada continuada) assumiu a tônica de suas (pro)posições via Pedagogium.

${ }^{3}$ Dentre esses ordenamentos, estão incluídos comunicados aos inspetores de ensino tratando de assuntos diversos, tais como: substituição de professores por alunos-mestres e avisos de conferências pedagógicas.
} 


\section{Notas (auto)biográficas}

Consoante a abordagem (auto)biográfica que se assume, neste artigo, cabe indagar o que deve ser objeto do (auto)biográfico no âmbito da História da educação? Argumenta-se que tal vertente ou intento visa reconstituir a trajetória de educadores e/ou intelectuais que ocuparam a cena educacional (FREITAS, 2006) em um determinado espaço-tempo. Todavia, vale lembrar o cuidado de não enfeixar o biográfico em/por uma cronologia, como se a vida fosse um projeto pré-determinado, passível de uma descrição finalista (BOURDIEU, 1996).

Manoel Balthazar Pereira Diegues Júnior era filho do primeiro Manoel Balthazar com dona Maria Joaquina da Fonseca Diegues. Seu nome consta no Diccionario Bibliographico Brazileiro de Sacramento Blake (1900, p. 34); no ABC das Alagoas (BARROS, 2005) e nos esboços biográficos escritos por Vaz Filho (1962) e Craveiro Costa na Revista de Ensino de Alagoas (1927) em seção designada "os grandes educadores alagoanos".

Vale ressaltar que ter o nome não somente registrado nas fontes citadas, mas sobretudo, destacada a sua atuação, já indica o quão se pode perscrutar acerca do que propôs e/ou realizou de Diegues Júnior em seus contributos à educação alagoana. Tais documentos, além de trazer indicações para se buscar outras fontes, apontam, igualmente para fontes (auto)biográficas, entendidas neste trabalho como uma escrita por e de si mesmo para além da fonte per si, atentandose para (pro)posições do sujeito (auto)biografado. Portanto, a indicação destacada desde a Escola dos Annales de que tudo que informa algo do/sobre os homens em um dado momento histórico pode ser utilizado como vestígio para a pesquisa histórica vale, igualmente para a pesquisa (auto)biográfica.

A escolha do nome de Manoel Balthazar Pereira Diegues Júnior, nascido em Alagoas no dia 29 de outubro de 1855 e falecido em 29 de agosto de 1922 para figurar nessa narrativa histórica, considera a sua inserção em um movimento de geração, mas sobretudo de relações que são de várias ordens, com destaque para a educacional. Nesse contexto, sua inserção em sociedades, cargos e funções ocupadas, aliada ao seu reconhecimento por contemporâneos, mas paradoxalmente do seu desconhecimento na hodiernidade, possivelmente em decorrência da projeção que também teve seu único filho de igual nome: o reconhecido cientista social, Manuel Diegues Júnior.

Balthazar Diegues teve o curso secundário completado no Liceu de Maceió e em 1870 matriculou-se na Escola Normal. Em Recife, atuou como docente nos colégios Santa Genoveva e Dois de Dezembro, quando ainda cursava a Faculdade de Direito, tendo chegado a ser Diretor, nesse último. 
O seu engajamento fez-se notar também pela participação em várias agremiações e sociedades da época, tendo sido Presidente do Instituto Histórico e Geográfico Alagoano de 12 de julho de 1901 a 29 de agosto de 1922.

Diegues casou-se com quase sessenta anos, com a professora de piano Luiza Amélia Chaves Diegues. Era o mais velho dos cinco irmãos, sendo o mais novo - Joaquim Thomaz Pereira Diegues - também formado bacharel na Faculdade de Direito do Recife e professor do Liceu de Alagoas. Vale ressaltar que ser professor de um liceu implicava em reconhecimento de um saberpoder que não se restringia ao campo da educação, considerando-se que por dentro dessa instituição que as relações eram tecidas na administração, já que a causa da instrução mobilizou homens de notório saber em prol da instrução pública - a grande bandeira erguida pelos letrados a época. Ainda em relação as três irmãs de Diegues - Maria (Sinhá) Pereira Diegues, Laura Habenícia Pereira Diegues, Ana Benícia Pereira Diegues, destaca-se que, pelo menos duas, atuaram como professoras primárias.

Considerando que era comum aos letrados do século XIX, operar em muitos domínios, para além da formação que detinham; Diegues Júnior, oriundo e integrante do campo jurídico, atuou igualmente na educação, intervindo, inclusive na instrução pública, tendo exercido vários cargos ou funções, seja como professor, diretor de colégio, inspetor escolar, Diretor da Instrução Pública, dentre outras.

Vale ressaltar que a atuação de Diegues, demarcada por uma diversidade de cargos e funções administrativas, foi sempre voltada à modernização da educação, o que se deu em várias frentes e temporalidades, a exemplo da criação de instituições como o Instituto dos Professores (1886) e o Pedagogium (1891) com todos os dispositivos que agregava (as conferências pedagógicas, as publicações, a biblioteca). Além disso, integrou a equipe de redação da Revista do Ensino de Alagoas (1907), com reconhecidas intervenções na organização escolar, quando os "grupos escolares" se apresentavam como símbolo da modernidade educacional. Desse modo, seu reconhecido protagonismo, possibilitou que fosse referido como um homem de ação em prol do desenvolvimento da instrução; atento aos problemas, mas também as possibilidades que se apresentavam em cada época, uma vez que atuou desde o último quartel do século XIX até os anos de 1920. 


\section{Por quais meios, Diegues Júnior, atuou para a modernização da educação alagoana?}

De acordo com o objetivo já anunciado para este artigo - discutir as contribuições de Diegues Júnior para a modernização da educação alagoana e por quais meios atuou -, optou-se por destacar tais contributos ao tempo que se reafirma a relevância da abordagem (auto)biográfica pela possibilidade de se analisar sua interação com a sociedade em temporalidades e formas diversas. Nessa perspectiva, destaca-se nesta seção (pro)posições, produções e práticas protagonizadas por esse educador que ora atuou como intelectual e/ou expert, podendo ser caracterizada a sua atuação por cada um destes termos ou por sua combinação em função das condições e/ou formas sob as quais operou, produziu, posicionou-se.

Vale salientar que, não é escopo desse artigo discutir acerca das diversas acepções relacionadas aos conceitos supracitados, optou-se por indicar as que estão em sintonia com o contexto da atuação do educador em tela. Assim sendo, o conceito de expert que se considera consoante ao que protagonizou Diegues é o indicado por Silva Neto e Costa (2020, p. 6) nos seguintes termos:

[...] aquele sujeito/personalidade/especialista do meio escolar, distinguido por seus conhecimentos e atitudes, que detém a competência necessária para desempenhar uma tarefa, examinar uma situação e constatar fatos, recrutado pelo Estado, de modo a subsidiar tecnicamente uma decisão e promover a disseminação e implementação de mudanças educacionais, bem como a objetivação e a produção de novos saberes no campo pedagógico, com vistas à sua institucionalização.

Considerando-se proposição de fazer uso dos termos já mencionados, aliada a sua inserção em períodos históricos, ou mesmo em conformidade ao modo como foram referidos nas fontes; destaca-se que não se localizou nos documentos utilizados para este trabalho, nenhuma menção direta aos termos intelectual ou expert para fazer referência a um sujeito específico, neste caso a Diegues Júnior. Contudo, consta em dicionários dos séculos XIX, sobretudo os franceses, as acepções para os citados vocábulos, conforme apontaram em seus estudos, Silva Neto e Costa (2020).

Com relação ao termo expertise, adota-se a definição proposta por Morais (2017, p. 61) ao mencioná-la como “[...] reconhecimento da competência daquele que detém os saberes necessários para realizar tarefas que lhes são designadas".

Na mesma esteira de compreensão, concordando com Machado, Dorigão e Coelho (2016, p. 185) em relação ao uso do temo intelectual para além de uma definição ou atribuição, há que se atentar que o cuidado recai sobre o contexto histórico e de atuação dos sujeitos, de modo que para 
os citados autores "[...] não se pode desconsiderar aquilo que o autor diz dele mesmo ou o que se tem repetido pela historiografia educacional."

Mediante o que foi apresentado, ao indagar acerca da possibilidade de caracterização de um sujeito como intelectual, recorre-se mais uma vez às indicações feitas por Silva Neto e Costa (2020, p. 9) ao recomendarem que a "[...] a partir de sua trajetória pessoal e profissional e suas relações com seu meio, em seu momento histórico"; deve-se analisar se as características apontadas por Vieira (2011, p. 29) fazem parte dos aspectos contextuais da atuação e, posterior caracterização de um intelectual, quais sejam:

a) sentimento de pertencimento ao estrato social que, ao longo dos séculos XIX e XX, produziu a identidade social do intelectual; b) engajamento político propiciado pelo sentimento de missão ou de dever social; c) elaboração e veiculação do discurso que estabelece a relação entre educação e modernidade; d) assunção da centralidade do Estado como agente político para efetivação do projeto moderno de reforma social.

Considerando que por sua atuação e reconhecimento público, Diegues Júnior atendia as condições supracitadas, evidenciadas pela diversidade de frentes em que se engajou, a ponto de Costa (1927) ter assim se pronunciado sobre esse intelectual: Esse soube amar deveras a sua terra e ser útil à sua gente" [...] "Pelo que fez pela educação da mocidade bem pode ser um modelo cívico".

De antemão, salienta-se que além da possibilidade de articulação que se agrega entre o intelectual e o expert, ou do sujeito agindo enquanto tal, destaca-se que a atuação social e profissional de Diegues Júnior esteve pautada por essas condições, o que possibilita caracterizá-lo como intelectual do/no seu tempo.

Feitas essas considerações, apresentam-se as contribuições de Diegues a modernização da educação alagoana em suas múltiplas facetas de atuação, ora como intelectual, ora como um expert.

\section{A face do educador e os vestígios de uma atuação como expert}

Diegues Júnior trilhou pelos caminhos da docência adentrando, inclusive, a instrução elementar via administração ao ocupar por mais de uma vez a função de Diretor da Instrução Pública. No âmbito desta função antagonizou com o ilustre professor de Pedagogia da Escola Normal, Dr. Joaquim José de Araújo, que inclusive havia sido seu professor.

Ainda que o discípulo nutrisse um profundo respeito pelo mestre; em nome da modernidade educacional, ou de um poder-saber do qual se encontrava investido, Diegues Júnior, invocou dessa relação à autoridade associada ao saber para pronunciar-se publicamente com vistas a esclarecer a questão em que criticou a formação dos professores para atuar nas escolas primárias, 
segundo ele ainda pautada em Daligault e não no que havia de mais moderno à época, a saber: o método intuitivo e as lições de coisas. Assim sendo, fez veicular no jornal $O$ Orbe sua explicação ao professor de Pedagogia, o Dr. Joaquim Araújo. Assim, argumentou Diegues:

Conheci o compendio de Daligault e o estudei com aquella lucidez de intelligensia e força de comprehensão que tantas vezes enthusiasmou meu ilustre mestre, o Dr. Araújo, quando via em mim bem empregadas suas lecções; e conheço theorica e praticamente a excelência de outro regimem que com $\mathrm{mm}$. Pape Carpentier substituiu na França a rotineira lecção de Daligault. (O ORBE, 17/09/1886).

Depreende-se da declaração em destaque que a leitura e o conhecimento constituam valores significativos para Diegues, ao tempo que aponta para uma expertise enunciada ou (auto)reconhecida, o que lhe atribuía autoridade, neste caso, pedagógica. Nessa direção, caracterizálo como um expert pode estar associado ao que escreveu sobre ele, Craveiro Costa (1927, p. 39): [...] "Ilustre pela sua cultura, querido por sua bondade, senhor de todos os seus segredos de Pedagogia, cuja evolução acompanhava solicitamente, adaptando-se a todas as inovações da velha arte de ensinar".

Outra atuação que pode ser agregada a esta, refere-se à apropriação que fez do Relatório de Célestin Hippeau ${ }^{4}$ referente a República Argentina, no intuito de contribuir para um repensar dos métodos e práticas de ensino até então empregadas na instrução pública alagoana. Para tanto, fez circular na imprensa o Regimen Escolar, uma transcrição do Relatório de Hippeau. Nas duas situações ou posicionamentos, evidencia-se o quanto Diegues estava sintonizado com os autores que muito influenciaram os intelectuais brasileiros e que estavam em voga à época. Ainda na direção da modernização do ensino, declarou Diegues: "Não faço questão dos programmas pomposos, faço questão dos méthodos que aproveitem o tempo do alunno sem lhe cançar o cérebro com lecções importunas". (O ORBE, 17 de setembro de 1886).

Diegues em suas intervenções e (pro)posições soube bem recorrer a diversidade de conhecimentos e de leituras que incorporou ao seu vasto repertório intelectual. Nessa direção, também produziu compêndios para mais de uma disciplina, destacando-se a sua Gramática Elementar da Lingua Nacional (1876) e o Compêndio de Geografia e Cosmografia (1890), sendo oferecido esse último as suas alunas da escola normal, razão pela qual merece destaque essa obra, quando o (auto)biográfico se apresenta inscrito na/pela prática da docência. Assim registrou Diegues na citada obra: "esse trabalho é testemunho da solicitude que tenho por meos alumnos e alumnas, aos

\footnotetext{
${ }^{4}$ Este intelectual francês influenciou muitos intelectuais brasileiros do século XIX por considerarem suas ideias próximas a certa modernidade de ensino.
} 
do $2^{\circ}$ anno do curso normal de 1890 o dedico, especialmente como penhor de sympathia que sempre me mereceu a mocidade estudiosa".

No cargo de Diretor da Instrução Pública, Diegues apontou para a necessidade da formação docente, ao publicizar e recomendar ao Presidente do Instituto dos Professores Primários (1886) a participação do maior número de professores possível em uma exposição escolar a ser realizada na Bahia em janeiro de 1887, argumentando no citado expediente, que os professores se conferenciassem pelas razões e benefícios assim explicitados:

Convindo muito ao progresso da instrucção pública que os snrs. Professores
conferenciem entre si sobre as questões de educação e ensino e procurem se ajudar
mutuamente no sentido de transplantar para as escolas públicas desta provincia os
methodos avantajados que tanto preconisam os progressos da pedagogia [...]. (O ORBE,
17/09/1886).

Para Diegues as conferências agregavam os professores, além de contribuir com a sua formação e a socialização de saberes, razão pela qual ele participou de tantas. Ademais, as conferências poderiam favorecer a adesão e implementação das inovações pedagógicas nas escolas públicas.

Ainda com relação ao Pedagogium, objeto de esclarecimentos em Relatório encaminhado ao governador do Estado em 09 de abril de 1892, Diegues, não somente destacou sua importância e funcionamento, mas também reivindicou para si tal proposição:

\begin{abstract}
Dominado da idéa de proporcionar aos mestres meio de aperfeiçoarem sua instrucção, especialmente sobre os processos de ensino tão vantajosamente empregado nas escolas norte-americanas, allemãs, italianas e argentinas, em officio de 14 de fevereiro propuz a criação do Pedagogium, que se realizou no decreto de 12 de março de 1891. Esta instituição tinha eu lembrado em meu relatório de 1889, quando me convenci que os simples recursos do magistério não a podiam realizar no Instituto dos Professores. [...] Elle tem por fim: $1{ }^{\circ}$ Reunir os mestres em conferencia, de cuja utilidade ninguém pode duvidar, maxime entre nós onde são difíceis os meios de colher instrucção. 2. ${ }^{\circ}$ Proporcionar aos mestres bibliotheca e museo onde sem dispêndio possam ter os livros de que carecerem e onde escolham o material escolar de que se queira servir. $3 .^{\circ}$ Estabelecer cursos onde os mestres se aperfeiçoem nas matérias cuja instrucção desejem completar ou melhorar. 4. ${ }^{\circ}$ Publicar uma revista que será orgao do magistério alagoano, levando assim notícia de sua habilitação, merecimento e trabalhos. (RELATÓRIO, 09/04/1892).
\end{abstract}

Mediante o exposto e dialogando com as referências adotadas para este estudo, reafirmase a atuação de Diegues demandada em função da modernização da educação alagoana, mas igualmente por uma expertise que lhe era atribuída e reconhecida, notadamente por sua capacidade de propor, reunir e agir. 


\section{A elaboração da obra Consolidação das Leis da Instrução Pública}

Destacar um domínio formativo ou ramo de atuação de um sujeito é importante na medida em que esta formação embasa ações e reconhecimentos que demarcaram inserções e produções referendadas por um saber-poder compartilhado e distinguidos pela sociedade.

No ano de 1878, Diegues participou do Congresso Agrícola do Recife, como representante de Alagoas, posicionando-se em relação à educação profissional rural, tipo de ensino por ele defendido e para o qual apresentou um programa, sugerindo conteúdos e práticas. De acordo com Diegues Júnior (o filho), o citado programa foi uma “[...] peça de interesse para a história do ensino no país", em que defendia a adaptação das escolas às localidades (escola regional) nos seguintes termos: "O ensino primário deve ser geral, mas útil, prático e não abstrato; se a escola é da cidade, o ensino seja inclinado ao comércio e às letras; se a escola é do campo, o ensino seja inclinado à agricultura e conhecimentos conexos". (DIEGUES JUNIOR, 2012, p. 148). Desse modo, o programa apresentado por Diegues Junior pode ser considerado uma (pro)posição política, mas também pedagógica.

Visando situar o contexto de elaboração da obra citada no título dessa seção, cabe ressaltar que a legislação educacional nas Províncias no período do Imperial estava à mercê de movimentos de natureza econômica, política e cultural que repercutiam no não cumprimento das leis e na morosidade por aprová-las, o que se caracterizava por um constante recomeço, consideradas também as sucessivas entradas e saídas de administradores.

Nessa direção, o Presidente da Província das Alagoas, José Cesário de Miranda Monteiro de Barros, assim se pronunciou:

\footnotetext{
A legislação sobre instrucção publica é um cahos, que convém quanto antes dissipar, tornando-a perfeita e clara para a bôa regularidade deste importante ramo do serviço público. Regem os regulamentos de 1853, 1865 e 1870 e várias disposições esparsas na legislação provincial, contradictorias umas, mal combinadas outras, insufficientes quasi todas para as exigências actuaes. (BARROS, 1888, p. 8-9).
}

Ainda no contexto dessa problemática em 29 de abril de 1889, o então presidente da Província das Alagoas, o bacharel Aristides Augusto Milton aprova a Consolidação das Leis da Instrução Pública (1889), conforme consta em paratexto que acompanha a citada obra, registrada nos seguintes termos: 
O Presidente da Provincia, attendendo á necessidade de reunir methodicamente, em um só acto, as diversas disposições de lei, regulamentos e divisões, concernentes á instrucção publica, esparsas na legislação da Provincia; Resolve approvar, mandando que seja observada, para todos os effeitos, a consolidação, que a este acompanha, elaborada de sua ordem pelo Bacharel Manoel Balthazar Pereira Diegues Júnior, ex-director geral da mesma instrução pública, e ordena que neste sentido espeçam-se as necessárias communicações.

Mediante o exposto, depreende-se que a obra visava atender a uma necessidade de organização da legislação educacional e, igualmente, da administração da época; ao tempo que se institui como um trabalho que coube a um intelectual com experiência política, jurídica, administrativa e educacional, como era o caso de Diegues Júnior.

Destaca-se da obra Consolidação das Leis da Instrução Pública (1889) o caráter de inovação e de compilação, mas também de reconhecimento da sua formação de bacharel. Na citada obra, Diegues Júnior, recupera, seleciona, reúne, preserva e veicula as “decisões, regulamentos e instruções” como vestígios do que se pensou e foi normatizado para a educação de uma época, e que nos foi legado pelo Império do Brasil na Província das Alagoas.

Trata-se de uma compilação da vasta legislação educacional que regulava a instrução pública de Alagoas. Cabe destacar que a citada produção, ao tempo que se institui como um documento pode também ser considerada um Guia de fontes seletivo com potencial para se investigar acerca da legislação educacional de Alagoas em suas permanências e mudanças.

Reafirma-se por essa atuação ou produção, a possibilidade de atribuir a Diegues tanto a caracterização do agir de um intelectual quanto de um expert, sobretudo pela demanda que lhe foi incumbida pelo Estado e por sua institucionalização enquanto documento.

Desse modo, ao laborar a Consolidação das Leis da Instrução Pública, sob a condição de demarcar as letras das Leis que ainda estavam em vigor, conforme o contexto ou pretexto de sua produção, Diegues Júnior, situou cada excerto da compilação da Lei com a fonte regulamentadora correspondente - realizando assim um trabalho de "ajuntar o disperso, abreviar o longo, apartar o seleto. ${ }^{5}$ "

Parafraseando Rui Barbosa avalia-se que por essa produção, Diegues imprimiu sua memória e contribuição, estatuando-se pelos benefícios que lhe herda(ram)mos em/por meio de atos e impressos que favorecem a construção de (des)conhecimentos acerca da escolarização em Alagoas.

\footnotetext{
${ }^{5}$ Epígrafe utilizada por Rubens Borba de Moraes no prefácio do título Livros e Bibliotecas no Brasil Colonial, de autoria de Antônio de Sousa de Macedo.
} 


\title{
3.3 Uma proposta e reconhecimentos em prol da moderniz̧ação da educação alagoana
}

\begin{abstract}
A Diegues Júnior, o grande educador alagoano, deve Alagoas a fundação do seu primeiro grupo escolar. É o mais antigo do Estado. Foi primeiramente uma organisação irregular, em casa imprópria na qual Diegues Júnior alojou todas as escolas do seu districto, dando a forma mais de escola reunida que de grupo escolar. A organisação foi se fazendo quase a revelia official. Mas a semente ficou plantada. O governador Baptista Accioly foi ao encontro daquella tenacidade victoriosa, construiu o bello edificio da Pajussara (REVISTA DE ENSINO, n. 3, 1927, p. 74).
\end{abstract}

A partir do excerto apresentado é possível tecer algumas considerações acerca do homem de iniciativa e de ação que fora Diegues Júnior: atento as inovações e necessidades educacionais que se apresentavam ao seu tempo, fazendo ecoar e realizar as discussões mais prementes empreendidas por homens de letras e/ou da administração em prol daquela que foi a mais defendida bandeira para o desenvolvimento do país - a instrução pública.

Corroborando Sirinelli (2003) ao referir que a base da atuação e/ou legitimação de um intelectual é o seu engajamento na vida da cidade, aliada ao seu reconhecimento, na esfera social, reafirma-se que Diegues Júnior pode ser então considerado um intelectual do seu tempo. Ainda nessa perspectiva, esse reconhecido intelectual atuou como construtor de representações por meio do seu discurso, haja vista as pessoas que conseguiu agregar em comissões, além das inúmeras declarações que lhe foi dirigida em eventos e homenagens póstumas.

O falecimento de Diegues Júnior, por exemplo, foi noticiado como uma grande perda para o Estado de Alagoas, mas também como um grande ganho pelo muito que fez em/por sua terra. O Jornal do Brasil (1922, p. 4) assim registrou: “[...] a quem o Estado de Alagoas deve grandes serviços, no tocante ao culto das letras, da educação de sucessivas gerações e do desenvolvimento scientífico e industrial [...]".

No jornal Diário de Pernambuco, exaltou-se a sua atuação, reclamando inclusive do seu tardio reconhecimento em sua cidade natal. Registrou o citado jornal:

[...] exerceu sua actividade em varios misteres, mostrando sempre a mais severa exacção no cumprimento dos seus deveres, lúcida intelligencia, cabedal farto de illustração e enorme capacidade de trabalho. Foi no exercício das funções de professor que mais se salientou [...]. Ultimamente era o Dr. Diegues Júnior um dos homens mais populares de Maceió, que tardiamente reconheceu a beleza e qualidades de seu espírito bondoso (DLARIO DE PERNAMBUCO, 1923, p. 2).

Mediante aos reconhecimentos mencionados, destaca-se também como tributo a memória de Diegues, a inscrição do seu nome, ainda possível de ser visto na atualidade, em um prédio imponente do bairro da Pajuçara, em Maceió, onde se lê: “Grupo Diegues Júnior” - mais que um tributo ao intelectual, um patrimônio da memória da educação alagoana. Se a importância dos 
intelectuais pode ser materializada por dar nome a escolas, reafirma-se que Diegues teve sua atuação reconhecida em prol do desenvolvimento da educação e da cidade de Maceió/AL.

Ademais, Diegues Júnior foi reconhecido pelos letrados da época, de modo particular, quanto pela sociedade, de modo geral, como um homem de extraordinária projeção, destacado por aspectos que lhes eram atribuídos como: retidão de caráter, erudição copiosa, administrador de talento e sabedoria, sendo ainda um grande patriota.

Considerando que estudos historiográficos que abordam a História dos intelectuais, geralmente associam essa característica aos homens de letras que estiveram à frente da discussão e defesa da organização do ensino público brasileiro, isso nos provoca a reflexionar sobre a possibilidade de atribuir o predicado de intelectual ao aludido educador alagoano.

Nessa perspectiva, assume-se a necessidade de volver o olhar para a época do indivíduo, haja vista um primeiro entendimento de que o termo "intelectual," define-se a partir das suas representações num dado contexto histórico.

Para esboçar uma definição do que era ser intelectual nas décadas finais do Brasil Império, recorremos a Vaz Filho (1962, p. 1) ao escrever sobre Diegues Júnior:

\footnotetext{
Os homens de inteligência que no passado serviram á sua terra e ao seu povo, foram todos êles obreiros desta civilização que trouxe ao mundo novos horizontes de progresso e de saber nos diferentes ângulos das nossas atividades. Não obstante as decepções e dissabores por que as vêzes passamos, é forçoso reconhecer que em nosso País e particularmente em cada Estado surgiram homens que, pela inteligência e amor à terra do seu nascimento, muito contribuíram para a grandeza da Pátria comum. Em nosso Estado, extensa é a galeria de homens notáveis, que, pelo saber e patriotismo, se destacaram entre todos quantos concorreram para elevar bem alto o nome do Brasil e de Alagoas.
}

Mesmo não se referindo, diretamente, ao termo intelectual, nas palavras de Vaz Filho é possível observar que os "homens de inteligência" definiam um grupo de sujeitos que pensaram e propuseram ideias com vistas à elevação da sociedade de seu tempo, tanto no campo material como moral. No Brasil Império, em particular, revestidos pelo ideário de construção de uma "cultura civilizada," um grupo seleto de homens - e aqui entendemos que correspondem aos "homens de inteligência", dos quais fala Vaz Filho - preocupou-se em expressar por vias diversas (produções avulsas, imprensa, etc.) meios de se atingir tal ideário, inserindo a escolarização como eixo principal de construção dessa cultura.

No exercício de funções diversas, no cenário público da época, (bacharéis, políticos, professores primários e secundários, médicos, geógrafos, etc.), estes homens, sentiam-se capazes de refletirem sobre as problemáticas de seu tempo e legislarem sobre as mesmas. 
Cabe destacar que, a participação em sociedades científicas e/ou literárias existentes naquele contexto, implicava a esses homens estarem numa posição privilegiada no meio público e atuarem de forma direta na organização do Estado; compartilhando ideais comuns aos seus pares, o que Alonso (2000) irá definir como ação política do sujeito dentro do meio ao qual pertence. Deste modo, os discursos produzidos e divulgados no interior dessas sociedades, repercutiam na vida pública do período e, consequentemente, projetavam novas maneiras de pensar a organização social daquele espaço.

Considerando-se a diversidade de espaços de inserção e atuação de Diegues é possível confirmar traços comuns aos homens de uma época e geração, que se designaram como representantes do progresso social, razão pela qual pode ser considerado um intelectual, além de ter contribuído para o movimento de modernização da instrução, inclusive agindo para tal intento, como foi o caso de organizar as escolas reunidas.

Ademais, sua expertise no âmbito das funções ou cargos que assumiu no contexto da educação alagoana, sendo igualmente reconhecida por seus contemporâneos, também permitem considerá-lo um expert, dada a sua contribuição para "[...] sistematizar saberes específicos para o funcionamento escolar, tais como a elaboração de programas para o ensino, cursos para professores, além de outras atividades ligadas à sua expertise" (ALMEIDA; VALENTE, 2019, p. 324). Portanto, mediante a atuação de Diegues Júnior em prol da modernização da educação alagoana, reafirma-se que atuou tanto quanto um intelectual, quanto um expert em educação, ou ainda como um intelectual-expert.

\section{Considerações finais}

$\mathrm{Na}$ escrita deste artigo, tratou-se da trajetória da atuação educacional de um sujeito com relevante atuação profissional em seu tempo, o educador alagoano Manoel Balthazar Pereira Diegues Júnior (1852-1922).

Para tanto, recorreu-se a uma diversidade de fontes que abarca dimensões do pessoal, mas, sobretudo do profissional, do social publicizado, de modo que os elementos ou condições estruturais ou profissionais acessadas por Diegues Júnior também fossem evidenciadas.

Assim sendo, ainda que se tenha operado com as atribuições de intelectual e expert para as diversas formas de atuação de Diegues Júnior para modernização da educação alagoana, concordou-se com Oscar Neto e Costa (2020, p. 9) ao destacarem que “[...] mais do que classificar pessoas como intelectuais ou experts, o importante é identificar quais saberes produziram e fizeram circular". 
Conclui-se, reafirmando que a atuação de Diegues Júnior para a modernização da educação alagoana se deu sob a tríade conhecimento, autoridade e inserção em diversas instituições, desempenhando funções, produzindo e compartilhando saberes que foram publicizados. Deste modo, produziu compêndios, sistematizou a legislação educacional alagoana em função de suas transformações e modernização, além de ter proposto dispositivos de e para formação dos professores, a exemplo das conferências pedagógicas e a Revista de Ensino.

Diegues posicionou-se em diversas ocasiões por meio da imprensa, mecanismo de demarcação de (pro)posições mobilizadas à época em prol da instrução. $\mathrm{Na}$ função de redator do jornal $O$ Orbe, fato que não é mera informação, mas, sobretudo condição material, objetiva de atuação/visibilidade enunciou posicionamentos, dando a ver sua atuação.

Há que se destacar que Diegues fazia parte de um seleto grupo de professores que atuavam no ensino secundário, e no seu caso também na Escola Normal, tendo exercido funções políticas e administrativas.

Por fim, com relação à multiplicidade de inserções sociais ou campos de atuação mobilizados por Diegues Júnior, vale destacar que não foi esta uma exceção, mas uma quase extensão daqueles que atuavam no ensino secundário, particularmente nos liceus, cuja identidade profissional ou professoral não prescindia da participação ativa em setores da administração da instrução pública; além de assumirem a condição de autores de livros.

Nessa perspectiva, indica-se que Diegues Júnior atuou ora como um intelectual ou um expert, considerando-se que atendeu a demandas solicitadas pelo Estado, mas também em prol da cidade, da modernização da instrução, mas, sobretudo como professor - "[...] a feição mais bela do seu espírito" - conforme destacou Costa (1927, p. 39).

Decerto, Diegues Júnior teve uma vasta atuação no cenário sociopolítico de Alagoas desde o último quartel do século XIX. No entanto, foi como educador que se fez lembrado por Barros (2005), Vaz Filho (1962) e Costa (1927).

\section{Referências}

ALMEIDA, A. F.; VALENTE, W. R. Os experts e a produção de saberes para a docência: Primeiros estudos do acervo Lydia Lamparelli. Linhas Críticas, 25, p. 318-332. 2019. Disponível em: https://doi.org/10.26512/lc.v25i0.23109/.Acesso em: 12 mar. 2021.

ALONSO, A. Crítica e Contestação: o movimento reformista da geração 1870. Revista Brasileira de Ciencias Sociais - RBCS, v. 15, n. 44, p. 35-54, 2000. Disponível em:

https://www.scielo.br/pdf/rbcsoc/v15n44/4146.pdf. Acesso em: 10 fev. 2021. 
BARROS, F. R. A. $A B C$ das Alagoas: dicionário bibliográfico, histórico e geográfico das Alagoas. Brasília: Senado Federal, 2005.

BARROS, J. C. M. M. Falla com que o Exm. Snr. Dr. José Cesário de Miranda Monteiro de Barros abriu a $1^{a}$ Sessão da 27ª Legislatura da Assembléa Provincial das Alagoas Maceió: Typ. do Cônego Antonio José da Costa, 1888.

BLAKE, A. V. A. S. Diccionario bibliographico brazileiro. Rio de Janeiro: Typ. Nacional, v. 6, 1900.

BOURDIEU, P. A ilusão biográfica. In: AMADO, J.; FERREIRA, M. M. Usos e abusos da história oral. Rio de Janeiro: Editora da FGV, 1996, p.183-191.

COSTA, João Craveiro. Os grandes educadores alagoanos (Diegues Júnior). Revista de Ensino, n. 4, 1927.

FREITAS, A. B. A produção dos estudos biográficos em Sergipe e as principais contribuições para a história da educação. In: SOUZA, E. C. Autobiografias, histórias de vida e formação: pesquisa e ensino. Porto Alegre. EDIPUCRS: Salvador: EDUNEB, p. 145-160, 2006.

MACHADO, M. C. G.; DORIGÃO, A. M.; COELHO, G. F. As pesquisas com intelectuais em História da Educação: um campo profícuo. Revista HISTEDBR On-line, Campinas, SP, v. 16, n. 67, p. 175-188, 2016. Disponível em: https://periodicos.sbu.unicamp.br/ojs/index.php/histedbr/article/view/8645233. Acesso em: 28 mar. 2021.

MORAIS, R. S. Experts educação e a produção de saberes no campo pedagógico. REMATEC, v. 12, n. 26, set./dez., 2017. Disponível em:

http://www.rematec.net.br/index.php/rematec/article/view/110. Acesso em: 25 mar. 2021.

SCHUELER, A. F. M. Professores primários como intelectuais da cidade: um estudo sobre produção escrita e sociabilidade intelectual (Corte imperial, 1860-1889). Revista de Educação Pública, v. 16, n. 32, p. 131-144, set./dez., 2007.

SILVA NETO, O.; COSTA, D. A. Expert, intelectual e/ou polímata? Uma contribuição para a História da Educação Matemática. History of Education in Latin America - HistELA, v. 3, e23450, p. 1-17, 2020. Disponível em: https:// doi.org/10.21680/2596-0113.2020v3n0ID23450. Acesso em: 14 mar. 2021.

SIRINELLI, J. F. Os intelectuais. In: RÉMOND, R. (Org). Por uma nova bistória politica. Rio de Janeiro: Editora FGV, 2003, p. 231-269.

VAZ FILHO, A. Alagoanos Ilustres: esboços biográficos. Maceió: IHGAL, v. 2, 1962. ( ${ }^{\circ}$ de localização do livro: AL1 P4 L103).

VIEIRA, C. E. Erasmo Pilotto: identidade, engajamento político e crenças dos intelectuais vinculados ao campo educacional brasileiro. In: LEITE, J. L.; ALVES, C. (Orgs.). Intelectuais e história da educação no Brasil: poder, cultura e políticas. Vitória: EDUFES, 2011, p. 25-54. 


\section{Documentos pesquisados}

DIEGUES JÚNIOR, M. B. P. Consolidação das Leis da Instrução Pública. Maceió/AL, 1889.

DIEGUES JÚNIOR, M. B. P. Educação: Regimen escolar. O Orbe, Maceió, 15 de setembro de 1886, p. 2.

DIEGUES JÚNIOR, M. B. P. Educação: Instituto dos Professores Primários. O Orbe, Maceió, 21 de maio de 1886, p.1.

DIEGUES JÚNIOR, M. B. P. Compendio de Geographia e Cosmographia. Maceió: Typ. D’A Ordem, 1890.

DIEGUES JÚNIOR, M. B. P. Relatório que ao exm. Sr. Governador do Estado apresentou o diretor geral da instrução pública em 09 de abril de 1892.

Jornal Diário de Pernambuco, n. 1 (03/01/1923).

Jornal do Brasil, n. 209 (01/09/1922).

Revista de Ensino de Alagoas, n. 3 e 4, 1927. 